\title{
How did the work impact me? Reflections of the researchers and facilitators of BME success projects
}

\author{
Helen Catherine Barefoot, Nathan Ghann, Judy St John, Amanda Yip \\ University of Hertfordshire
}

\begin{abstract}
Programme leaders and members of programme teams attended inclusive teaching workshops focused on race equality. After the workshops, programme leaders were interviewed to discuss how they were going to implement inclusive practice enhancements. The core team who facilitated the workshops and conducted the interviews reflected on their experiences of leading change associated with reducing the BME attainment gap.

Considering a critical incident which they'd experienced during the workshop or during the interviews, they each wrote personal narratives to explore emotions which the incident had stimulated as well as consideration of how they'd responded at the time and what they could have done differently. The four narratives were considered to identify key themes. Two common themes identified were the stimulation of negative emotions (e.g. anger) and the inability to challenge comments and stereotyping assumptions at the time of the incident. Considering the results in light of literature associated with staff development, the use of personal narrative and leading diversity related change, in addition to autoethnographical thoughts associated with the authors' own experiences of race, racism and privilege, five recommendations for colleagues involved in race-related staff development were identified.
\end{abstract}

\section{Keywords: BME, Narrative, Critical Incident}

\subsection{Introduction}

The BME attainment gap (i.e. the difference in the percentage of white students achieving a first or upper second class degree (2i) compared to the percentage of black and minority ethnic (BME) students achieving a first or $2 \mathrm{i}$ degree) has been a long-standing concern within the UK higher education (HE) sector (Broecke and Nicholls, 2007; Berry and Loke, 2011; Equality Challenge Unit, 2017). The University of Hertfordshire is a post-1992 University with over 24,500 students, approximately $45 \%$ of whom are from BME backgrounds. The University has been committed to reducing the attainment gap and several institutional activities have together resulted in reductions in the attainment differential by ten percentage points (gap between Home/EU White and BME students in $2009=27 \%$ and in $2017=17 \%$ ).

In 2017, the University embarked on a HEFCE- (now Office for Students) funded collaborative project with five other institutions (Kingston University [Project Lead], University of Wolverhampton, University of Greenwich, University College London, De Montfort University) to use a value added (VA) metric to enable comparison of statistically-expected attainment and actual attainment for white and BME cohorts (taking into account entry qualifications and subject choice). Learning from colleagues at Kingston, the University of Hertfordshire developed a Tableau dashboard, showing VA scores to enable visual 
presentation of attainment data at the programme level, with the aim of enabling focused discussions with programme teams (Barefoot et al., 2018).

Programme leaders were invited to attend an inclusive practice workshop and to bring with them up to three members of the teaching team/module leaders. The workshops involved consideration of the VA data for their programme as well as the presentation of data analysed according to ethnicity, including national attainment data (ECU, 2017), institutional and academic school attainment data, and Destination of Leavers of Higher Education (DLHE) data. Consideration of the data enabled open discussions of race and racism.

The latter part of the workshop focused on inclusivity and enabled the sharing of disciplinaryspecific examples of race discussions within the curricula (prepared by the two workshop facilitators) to enable further contextualisation for the programme teams. Discussions of compassionate pedagogies and the importance of staff-student relationship and personal tutoring were also included. Prior to the workshop, delegates were asked to self-assess their current practice through the 'Inclusive Teaching' strand of the University of Hertfordshire Curriculum Design Toolkit (Barefoot, 2012) and they were also introduced to Kingston University's 'Inclusive Curriculum Framework' during the workshop.

Each workshop accommodated up to five programme teams and ran from April $6^{\text {th }}$ to July $5^{\text {th }}$ 2017. Twelve workshops ran, with a total of 162 participants representing thirty-seven programme teams.

As part of a Leadership Foundation for Higher Education (Advance HE)-funded project, programme leaders were interviewed at least one month after attendance at an inclusivity workshop, to identify enhancements that the programme leader intended to implement. The structured interviews explored the challenges associated with leading inclusive practice changes and with facilitating discussions of the sensitive topic of race; they also revealed good practice and identified intended actions for the academic year 2017-18 (Barefoot et al. 2018).

The inclusive practice workshops were facilitated by the Chair of the University's BME Student Success Working Group (BME SSWG) and the Student Transformation Lead in Hertfordshire Business School. The programme leader interviews were conducted by members of the BME SSWG: the Chair of the group, a Learning and Teaching Specialist from the Learning and Teaching Innovation Centre and the Programme Leader of the University's Joint Honours programme. These individuals therefore comprised the team which led the race-related staff development sessions and subsequent programme leader research.

Through reflective conversations about the workshops and through discussions about the interviews - as part of the data analysis process - it became apparent that difficult comments and incorrect assumptions associated with race, as made by workshop/interview participants, had stimulated complex feelings and emotions for the members of the team. The paper aims to explore the impact of facilitating race-related staff development sessions and conducting race-related research on the researchers' feelings and emotions through critical reflection and consideration of their own race via autoethnography-like approaches. 


\subsection{Literature review}

As the UK HE sector struggles to respond to such race-related challenges as the degree attainment gap between white and BME students (ECU, 2017), it is likely that institutions will embark on programmes of staff development, including 'unconscious bias' training, presentation of equality data to stimulate change and inclusive curricula workshops. Sara Ahmed's book 'On Being Included' (Ahmed, 2012) argues that institutions do not take responsibility for implementing diversity and that this falls to diversity workers and requires them to take ownership of the task. However, little has been written about the experience of running staff development activities associated with race equality and no-one appears to have explored the emotional impact on facilitators who find themselves exposed to some very challenging opinions during race-focused discussions. Given the limited evidence base, the literature review draws on sources associated with leading diversity-related change, staff development and the reflective accounts of researchers within race studies.

\subsection{Leading diversity-related change}

Within HE, a key reason for implementing diversity-related change is to create greater parity of experience and outcome for students from diverse backgrounds, yet leading diversity initiatives can be fraught with challenge. In her discussion on leadership strategies for addressing the politics of diversity, Kezar (2008) identifies that "people do not operate in rational ways and will resist issues about which they have fears", recognising that challenging conversations, inappropriate comments and uninformed opinions may surface. She argues that "existing groups defend the resources and power that they have..." which may result in individuals' adopting entrenched positions despite contradictory evidence. Kezar (2008) also identifies the importance of persistence, understanding that changing groups' opinions and behaviours takes time and that advocating for change over a lengthy period does tend to get results (Baldridge et al., 1977; Cohen and March, 1974).

Kezar's interviews with twenty-seven college presidents and their experiences of leading institutional diversity initiatives enabled her to identify six important strategies:

1. Develop coalitions and advocates (e.g. gaining support from various interest groups including staff, students, administrators, alumni, community groups).

2. Take the political pulse regularly (including understanding communication channels and identifying key individuals who can influence change).

3. Anticipate resistance.

4. Use data to neutralise politics and rationalise the process.

5. Create public relations campaigns and showcase success (including helping people to understand different perspectives).

6. Capitalise on controversy for learning and unearth interest groups (Kezar, 2008).

Although not necessarily leading institutional change, some of the strategies discussed by college presidents are likely to be applied by staff developers and researchers during their race-related activities including; taking the political pulse; anticipating resistance; and using data to neutralise politics and rationalise the process.

\subsection{Staff development approaches}

In considering the role requirements of staff development leaders, Blackmore et al. (2003) explore an equality and diversity scenario to consider skill requirements. The scenario 
outlines the need to address the Special Educational Needs and Disability Act, 2001. Although this is outdated and has been superseded by the Equality Act (2010), the attributes for successful staff development that Blackmore et al. identify could well be adapted and applied to race-equality staff-development activity:

- Capabilities- good understanding of the context and the attitudes of colleagues

- Skills - excellent presentation skills

- Knowledge - in-depth knowledge of legislation and data/evidence base

- Attitudes - positive views about supporting students from diverse backgrounds

- Values - a strong commitment to race equality (adapted from Blackmore et al., op.cit.).

When considering staff development associated with diversity training, it is important to consider not just the skills/attributes required by the facilitator, but also the range of approaches that may be used within staff-development sessions and the possible responses from delegates which they may elicit.

Classic approaches may include informative/enlightenment activities which raise awareness of biases against particular groups and promote the benefits of diversity within a student body. Examples could draw on a financial argument as well as encourage participants to take the perspective of members of other groups (Dovidio et al., 2004). Pendry et al. (2007) identify some limitations of this focus, as it is not easy to persuade members of traditionallyadvanced groups to change biased behaviours. They also suggest that it would be naïve to expect prejudice - based on incorrect assumptions - to stop once evidence disputing the assumption has been presented, since prejudice is underpinned by strong affective components - i.e. positive or negative emotions - (Dovidio et al., op.cit; Milton, 1972; Pettigrew and Tropp, 2000).

Dissonance approaches have also been applied within diversity training and include such examples as 'Walking through white privilege (WTWP) exercise', developed by McIntosh (1988), and the 'Blue-Eyed/Brown-Eyed exercise', designed by Jane Elliott over thirty years ago (2017), where one group is subjected to discriminatory behaviours and personal attacks by a facilitator and the other group members. Both of these exercises aim to evoke emotional dissonance or guilt and hence stimulate individuals to take personal responsibility for inequity. The risk of such approaches is to reinforce already-established 'inside' and 'outside' groups, owing either to guilt or anger - e.g. white people being blamed for privileges extended to them through no 'fault of their own' (Stewart et al., 2003).

Newer approaches include activities which create awareness of one's own biases, such as the Implicit Associate Test (IAT) (Project Implicit, 2011), in which participants take an online test to measure their hidden or implicit bias against a specific group (e.g. race). The assumption is that the discomfort that arises from being aware of one's unintentional bias will have a positive impact upon future behaviours (Pendry et al., op.cit.; Monteith et al., 2001).

It could therefore be argued that, in addition to the attributes identified by Blackmore et al. (op.cit.), facilitators of diversity-related staff development must have an in-depth understanding of the types of activities they incorporate and of the possible responses evoked in participants. It would also be pertinent for the facilitators to have considered their 
own biases, which could be explicitly or implicitly affecting their design of the training, especially if they were asking participants to consider their own biases and privileges.

\subsection{Reflective narratives}

Since, as mentioned previously, there is limited information associated with staff developers' experiences of race equality training, the authors looked to the larger body of evidence produced by educators teaching about race and racial dynamics in the classroom, as well as to the reflections of researchers into race-related matters in education.

The personal narratives of Funmi Amobi (2007), Rita Kohli (2008) and Stephen Brookfield (2016) all use reflective analysis to consider their practice in teaching future teachers about race. Interestingly, all three draw on critical incidents, from their lives and careers, which influenced their current approaches, and all three explore their own racial identify in relation to their practice.

Amobi (2007) writes about initially being a messenger and moving from "safe dialogues" with a conciliatory message aimed at changing individual students' attitudes without "white students feeling persecuted" - to implementing "courageous conversations on race". Using an 'external' narrator, via a three-part video (Closing the Achievement Gap, The Video Journal of Education, 2002), to raise uncomfortable points for some white students, Amobi was able to pose discussion questions associated with whiteness and white privilege, including "How do white teachers see 'other' students?'

Kohli's research (2008) considers the impact of white cultural dominance in schools and reviews the personal narratives of nine women of colour enrolled in an undergraduate education programme. The results showed that all nine participants had experienced racism and had been taught to perceive the dominant white culture as better than their own. Within the paper, Kohli also reflects on her own educational upbringing as well as her initial work within education:

"Reflecting back on my own education, there have been numerous moments when teachers made comments or acted in ways that prioritized white cultural values over my own. Whether in regard to my language, my religion, or my traditions, I have been taught in both subtle and blatant ways that the cultural knowledge of my family has less worth than that of the dominant white culture. What is even worse is that, as a teacher, I carried this learned perspective with me into the classroom and was instilling a hierarchy of white cultural superiority into the minds of my young students."

Kohli argues that encouraging trainee teachers of colour to reflect upon and heal from the racism they have endured will help them to think about their own culturally-relevant, raciallyconscious teaching strategies and to inform teacher-education programmes that often lack strategies and curricula that speak to the needs of teachers of colour (Kohli, op.cit.).

Within a chapter in his book, Brookfield (2016) discusses the importance of white educators' sharing personal narratives about their struggles of their own learned racism to help people understand and challenge the persistence of structural and systemic racism. Arguing that racism is learned through everyday speech, media images, peer groups and friendships, education and family, resulting in the ideology of white-supremacy seeping into our consciousnesses, he shares his own narrative of a childhood within a context of white 
supremacy (Brookfield, op.cit.). Through critiquing his own experiences and researching repressive tolerance (Marcuse, 1964), Brookfield advocates that educators should disclose how learned racism has framed their interactions.

In his research into the experiences of Black African service users of the UK National Health Service (NHS), Isaac Tuffour (2018) discusses the challenges he faced as an 'insider' researcher (Narayan, 1993), sharing characteristics with his research participants (including being Black, African and a first-generation immigrant). Tuffour (op.cit) identifies the benefits this brought in establishing rapport with participants and inspiring trust and acceptance, as well as enabling unspoken understanding. However, he lists such disadvantages as participant narratives' triggering "a tidal wave of sentiments" and the difficulty of suspending his own feelings (owing to his insider empathy), as well as his awareness of the existing power and politics of the research site (Tuffour, op.cit).

From the personal narrative articles, it is evident that reflecting on and being explicitly aware of one's own racial identify and how that influences behaviours, interactions, activities and reactions to situations, are very important in race-related education and research. Identifying one's own position within the context of the discussion is perhaps lacking within the discussions of staff development and this paper attempts to do that through its personal written reflections on a critical incident experienced during the leadership of race-focused workshops and research.

\subsection{Methodology}

Critical-incident analysis is frequently used within educational research. The analysis aims to identify the issues that have provoked strong feelings and, through structured reflection, individuals consider possibilities for future actions (Society for Education and Training, 2016).

Data for this article were collected as part of a reflective process carried out by the two facilitators of inclusive-practice workshops and two researchers involved in the interviewing of programme leaders.

Considering race, ethnicity, gender and the experience of working within $\mathrm{HE}$, the participants were:

1. a Black, British African-Caribbean female, who has worked in HE for over fifteen years

2. an Asian, Malaysian-Chinese female, who has worked in HE for over ten years

3. a Black, British male, who has worked in HE for over five years

4. a White, British female, who has worked in HE for over fifteen years

Participants 1 and 2 conducted interviews with the programme leaders and participants 3 and 4 facilitated the inclusive teaching workshops together. In relation to this paper, the participants were also the 'researchers' and so collaborated to agree the reflective questions that each would be asked in order to develop their personal narratives.

The research was conducted in accordance with the University of Hertfordshire's ethics protocol: "Protocol for reflective practitioner work by academic staff" (version 09.0, Appendix I, University policies and regulations RE01). 
The four participants were asked to provide written narratives of a critical incident that they'd experienced. The participants each wrote only one narrative and were asked to identify the incident that was most difficult for them. There were no explicit exclusion criteria in relation to the content of the narrative, but participants were asked to write their narratives independently and were asked to respond to the following:

Please think about a critical incident that you experienced when either interviewing a programme leader or running an inclusive practice workshop:

1. What was the critical incident?

2. How did it make you feel?

3. What did you do at the time and reflecting now, would you have done anything differently?

4. Imagining you were an observer in the situation, what did you notice?

By using a format for the reflection, the data collected were considered as four separate personal narratives and also coded to identify any recurring themes. Written narratives rather than interviews - were chosen, as the four participants all knew each other well and had already engaged in some informal conversations about particular incidents. Applying a formal interview method would have created an artificial environment, as individuals would have adopted the roles of 'participant' and 'interviewer' for each other, which might have led to an unspoken understanding between participant and interviewer and a possible failure of the participant to reflect fully on the incident and the feelings/emotions evoked. Within the results section, the participants are referred to as 'narrators', as the data were considered as personal narratives.

The use of personal reflection enables the authors to consider their experiences yet also requires an autoethnographical perspective, as each individual's analysis will have been considered through the lens of their own experience of race, racism and privilege.

\subsection{Results}

Four narratives were written, ranging in length from 420 to 935 words. Each narrative was reviewed by the authors and a summary of each incident outlined below, to provide context for the reader. The narratives were then considered together to identify key themes and common words, expressions and feelings.

Summary of critical incident number 1 :

During the interviewing of a programme leader, the programme leader established a pattern of responses which demonstrated a covert undermining of young black (mainly) African men.

Summary of critical incident number 2 :

The interview with a programme leader lasted for a very short period of time, as the programme leader was completely disengaged and uninterested. The programme leader also showed a lack of awareness of their student population and the BME attainment gap.

Summary of critical incident number 3 : 
Following a workshop, a programme leader stayed behind to discuss the data and their students. The programme leader thought that their students weren't good enough, implying that better students would be students who were not from ethnic minority backgrounds.

Summary of critical incident 4 :

During a workshop a programme leader discussed why they thought there was an attainment gap. The programme leader argued that they provided lots of support for their students but certain students had an attitude and didn't show up for lectures or tutorials. The programme leader was referring to their black male students.

Three of the four narratives $(1,3,4)$ described situations where programme leaders articulated deficit opinions about students of colour, making assumptions and demonstrating racial stereotyping. In two of the cases, this was directed towards black male students. Despite programme leaders' being presented with data and arguments which dispelled assumptions and stereotypes within the workshops, such explicit display of inherent biases affected the narrators.

The other narrative (critical incident 2) described a situation where the programme leader was completely disengaged and lacked awareness of any of the issues.

\subsection{Emotions and feelings evoked by the incidents:}

When considering the question 'How did it make you feel?' all four accounts described how the incident had made the narrator feel "angry".

- "My initial reaction was anger, then uncomfortable, shocked, mystified and a little bemused"

- "Initially I felt quite angry as the programme leader clearly seemed to show no interest..."

- "I was angry at first, appalled that a staff member could actively think of a group of people in simplistic terms ..."

- "I was angry with their racist attitude and frustrated that despite all the evidence we had presented and the discussion we'd had they still blamed our black students".

Other emotions described within the narratives are displayed in Table 1.

Table 1. Emotions identified in the narratives in response to the prompt question 'How did it make you feel?'

\begin{tabular}{|l|c|}
\hline Emotion identified & Frequency of mention \\
\hline Angry & 4 \\
\hline Worried & 3 \\
\hline Uncomfortable & 2 \\
\hline Disappointed & 2 \\
\hline Frustrated & 2 \\
\hline Confused & 2 \\
\hline Shocked & 1 \\
\hline Upset & 1 \\
\hline Appalled & 1 \\
\hline Concerned & 1 \\
\hline
\end{tabular}




\begin{tabular}{|l|c|}
\hline Tired & 1 \\
\hline Guilty & 1 \\
\hline Embarrassed & 1 \\
\hline Mystified & 1 \\
\hline Bemused & 1 \\
\hline
\end{tabular}

From analysing the statements, it is evident that some of the feelings were associated with direct reaction to words spoken during the incidents - e.g. 'anger', 'upset', 'shocked', 'appalled', 'uncomfortable' - whilst other emotions reflected feelings of empathy - e.g. 'concerned' and 'worried'.

The word 'worried' was used in two of the narratives, but in different contexts: the first, in relation to worry for the students (narrative 3 ) and the second in relation to concern for the feelings of the co-facilitator and a postgraduate (PG) student who was a participant in the workshop (narrative 4):

- "...but then I felt worried. Worried that any students they would interact with would be exposed to their inherent biases..."

- "...I was very concerned for the PG student and my co-facilitator, both of whom were black males - I was very worried about how their comments had made them feel".

\subsection{Responses at the time}

When reflecting on the incidents and responding to the prompt 'What did you do at the time and reflecting now, would you have done anything differently?', there were similar immediate responses to the situations where racial stereotypes were expressed. In the three cases, the narrators all identified that they did not directly challenge the comments. For example:

- "At the time I said nothing. Often when someone says something quite outrageous I am silent"

Through the narration, they all identified what they would have done differently. For example:

- "On reflection I should have challenged these more directly and maybe given them the opportunity to explain what they meant by certain statements".

Reflecting on critical incident number 2, the narrator thought about how she could have used additional data and specific programme information during the interview to engage the programme leader in discussion:

- "Reflecting now, what I would have done differently would be to meet this PL with some additional programme/module related data e.g. core module failure rates (split between white and BME), this may have allowed me to be a little bolder in getting the $P L$ to actually think about changing their own teaching practice..."

Narrators also identified that they could have tried to discover more about the thoughts of the individuals and such words as 'explore', 'probe', 'prompt' were used within the narratives.

\subsection{Observing the situation}

The final reflective question asked the narrators to imagine that they had observed the situation and to identify what they might have noticed. Responses included observations of 
the interviewer's/facilitator's remaining calm, as well comments regarding the expression of body language:

"There may also be instances where the interviewer may have sighed (either in anger or in disappointment) and struggled at many points to continue with the interview process".

The two narratives associated with the workshop-related incidents also included comments about the responses of others:

- "I noticed my co-presenter observing in the distance but waiting when to chime in..."

- "The moment the comments were spoken, the room went silent and delegates from other programme teams looked at the individual".

\subsection{Summary of results}

Although a small sample size, perhaps the two most common and arguably most important themes that were evident in the narratives were the:

- stimulation of negative emotions (e.g. anger)

- inability to challenge at the time of the incident

\subsection{Discussion}

It was perhaps unsurprising that a shared emotion experienced by all four narrators was that of anger and that other negative emotions (e.g. being shocked, upset, appalled) were described, since the narrators were all responding to incidents that either included racist, stereotyping comments or disengagement which dismissed and diminished the challenges faced by students of colour. Trying not to express this anger or other negative emotions they'd experienced seemed to stem from a position of trying to maintain neutrality and remaining calm. Race discussions have been described as 'difficult dialogues' (Sue, 2013) and one of the aims of the inclusive workshops and subsequent interviews was to create environments to enable open and honest discussions about race and to overcome the 'politeness protocol' which leads to potentially offensive or uncomfortable topics' being avoided, ignored or silenced (Sue, op.cit). The downside of this open dialogue is the exposure of people's inherent biases.

The incidents described by the narrators were not necessarily surprising, as the individuals all had previous experience in facilitating discussions about race either with colleagues and/or students, but the fact that the incidents occurred during or after staff development workshops designed to raise awareness of race discrimination and white privilege could explain the feelings of disappointment, frustration and confusion articulated within the narratives.

\subsection{The nature of the workshops}

Within the workshops, a number of data sets served to argue that differentials in degree attainment and employability outcomes could not be explained away through discussions of entry qualification, socio-economic background or gender, but that a white normative culture and the prevalence of white privilege within $\mathrm{HE}$ was inhibiting the outcomes for students of colour. The Equality Challenge Unit (ECU, 2018) emphasises the importance of using data during staff development workshops and it was hoped that presenting robust data from a range of sources, including programme-level data (Barefoot et al., op.cit.) would neutralise assumptions and uninformed opinion. As Pendry et al. (op.cit) discussed, it may have been 
naïve to think that this classical approach would have been sufficient to persuade some individuals to change established, biased opinions. However, the workshop also included a discussion of bias and encouraged workshop participants to complete Implicit Associate Tests (IAT) (Project Implicit, 2011) after the workshop to enable delegates to acknowledge their own biases. Rather than asking individuals to do the tests after the workshop, it might have been appropriate to ask delegates to complete the tasks prior to attendance. This might then have removed, or limited, some of the assumptions that were evident to the narrators in the workshops and subsequent interviews.

\subsection{Autoethnographical considerations}

Ellis and Bochner (2000) define autoethnography as "...an autobiographical genre of writing that displays multiple layers of consciousness, connecting the personal to the cultural". Three of the emotive words (Table 1) used in the reflections specifically relate to two of the individuals and connect them to their own racial identifies.

Narrator 3 reported feeling 'tired':

"This brings me to the last feeling, I felt tired. Tired of having to justify yet again that because a person is black or of an ethnic minority doesn't mean they are inherently less capable. That any disadvantages they may have are often due to historically structural or institutional inequalities".

Narrator 3 is black and his narrative identifies his own fatigue at having to have the same argument over and over again, something that most white people don't have to do as they are unaware of their own race in a society of whiteness. This frustration is expressed in a similar way by Reni Eddo-Lodge in her 2014 blog and subsequent (2017) best-selling book, 'Why l'm no longer talking to white people about race'.

One's own identity has to be considered when reflecting on the narrative statements. The experience discussed by narrator 3 is something that narrator 4 has not experienced, and will not experience, as a white person. Narrator 1 also discussed awareness of her own blackness during the interview she held with a programme leader. She wrote that the comments from the programme leader were "raising my hackles".

As a white person, narrator 4 identified feeling the 'self-conscious' emotions (Lewis, 2008) of guilt and embarrassment (Table 1):

- "I was very guilty that I did not immediately say something and that it was the PG student who challenged their opinions. He was extremely eloquent and spoke very well but I was the facilitator and I should have challenged their comments".

- "I was also embarrassed that a white colleague would say such things and I was acutely aware of my whiteness".

Recognising one's own racial identity and the impact this has had on one's own experiences in relation to privilege and sense of being 'outsider' or 'insider' has to be addressed and considered when facilitating race discussions or conducting race-related research. As Tuffour (op.cit) noted, the insider researcher can be both beneficial as well as problematic and Brookfield (op.cit) explicitly discussed his own racism and micro-aggressions within his teaching. 
Awareness of one's own identity may also influence the way one acts in a critical incident. For example, within the narratives, none of the four authors challenged the comments made at the time. The sense of having to maintain neutrality and remain calm over-rode their anger and prevented them from challenging racist comments and assumptions. Sue (op.cit) explores the challenges of facilitating racial dialogues in the classroom and recognises that race talk is often diluted and/or discussed in very superficial ways, for fear of offending others or creating potentially explosive situations. Amobi (op.cit) reflects on her own experience of cutting short her six-week course on multicultural education, following the outburst of a white male student during the week 5 session. Referring to the incident as 'the storm' she reflected on how she should have continued with her plans and on how, despite resistance to the 'message', she came to understand that it did not mean that the message should not have been told, but that there was an opportunity to retool the message for better telling.

Brookfield (op.cit) advocates the benefits of team teaching and recommends the use of such opportunities for colleagues to talk to students about how their own racial identifies framed the ways they negotiated decisions and employed different approaches. He also argues that a multi-racial teaching team is best placed to illustrate how the micro-dynamics of racism play themselves out. Identifying micro-aggressions and challenging them in the moment enables others to understand what a micro-aggression is and to consider the impact of micro-aggressions on people of colour. Narrators 3 and 4 co-facilitated the workshops and believed that the workshop delegates benefited from a multi-racial teaching team; however, as identified in critical incident 4 , narrator 4 did not act during a workshop and, through her silence, failed to challenge the racist assumptions that were being made. Brookfield (op.cit) suggests that, rather than trying to stifle a racist conversation, the inevitable pauses should be used to take plenty of time to think and then to respond. This approach would likely have benefited narrator 4 and also Amobi (op.cit), when she was confronted with the outburst during her teaching.

\subsection{Leading race-related activities}

Remaining calm and a maintaining a sense of neutrality were identified within the narratives, according with the responses of the college presidents, who identified the importance of not becoming defensive, but humbly questioning other people's rationale (Kezar, op.cit). This is articulated within the text of narrator 1 :

"On reflection I should have challenged these more directly and maybe given them the opportunity to explain what they meant by certain statements".

Kezar (op.cit) also identifies the importance of anticipating resistance. Although all authors did anticipate challenging conversations and resistance, it still did not reduce the impact of the incidents on their feelings. Having now reflected and identified how negative emotions were stimulated, they are arguably better prepared for similar future situations, as well being aware that, although their emotions will be stimulated, they will be better equipped to handle the feelings.

The authors all recognised the importance of resilience within their work. As identified by narrator 3 and Eddo-Lodge (op.cit), it can be exhausting to keep having to justify the rights of people of colour and the need for race conversations, so keeping focused on one's goal (Kezar, op.cit) is an aspect essential to the continuation of race-related staff development 
activity. In the authors' context, this is the removal of the attainment gap and the enabling of BME student success. The authors were all in agreement with the sentiments expressed in a quote from a college president:

"It's the students. They are what help me survive. When I hear their stories, when I see the changes we have made, I know I can take on the next battle..." (Kezar, op.cit).

\subsection{Recommendations for colleagues involved in race-related staff development}

Having reflected on their own experiences, both individually and as a group, the authors recognised the potential benefit of providing guidance/suggestions to support other HE staff involved with, or embarking on, race-equality staff development. Five recommendations are identified below:

1. Anticipate resistance and be prepared for negative emotions, such as anger and frustration, to be evoked during workshops - pause, take time to think and then respond rather than react.

2. Ask delegates to complete Implicit Associate Tests (IAT), prior to attendance at the workshop, and, if biases are then explicitly displayed in a session, use questions to explore what participants mean by certain statements.

3. Ensure you have the evidence needed to challenge assumptions, including quantitative information at the appropriate level of granularity (e.g. national, institutional and programme-level data), qualitative data and first-person narratives.

4. If possible, work in multi-racial teams so that facilitators can share how their own racial identifies inform their approaches and opinions.

5. Plan time to de-brief after workshop sessions and also encourage individual formal reflection on critical incidents, for discussion within facilitator teams.

\subsection{Conclusion}

This paper highlights the impact of race-related critical incidents on the leaders of staff development activities and race-related research. The authors recognised the benefits of formally reflecting on their experiences to identify how they could respond in future similar situations as well as recognising how their own racial identities influenced their responses to critical incidents.

\section{Reference list}

Ahmed, S. (2012) On Being Included. Racism and Diversity in Institutional Life.

Durham: Duke University Press. ISBN: 0822395320

Amobi, F.A. (2007) 'The Message or the Messenger: Reflection on the Volatility of Evoking Novice Teachers' Courageous Conversations on Race.' Multicultural Education, 14(3), 2-7. Available at: https://eric.ed.gov/?id=EJ762415 (Accessed: 1 August 2018). 
Baldridge, J.V. (1971) Power and conflict in the university. New York: John Wiley. ISBN: 0471045748

Barefoot, H.C. (2012) University of Hertfordshire Curriculum Design Toolkit. Available at: https://prezi.com/cibiptp5pa3d/curriculum-design-toolkit/ (Accessed: 1 August 2018).

Barefoot, H.C., St John, J. and Yip, A. (2018) Academic Leadership at the programme level to address the BME attainment gap. Leadership Foundation for Higher Education. Available at: https://www.lfhe.ac.uk/en/research-resources/research-hub/small-developmentprojects/sdp2017/hertfordshire-po.cfm (Accessed: 11 August 2018).

Berry, J. and Loke, G. (2011) HEA/ECU BME summit report. Available at: http://www.ecu.ac.uk/wp-content/uploads/external/improving-degree-attainment-bme.pdf (Accessed: 21 December 2017).

Blackmore, P., Stainton, C. and Wilson, A. (2003) 'Developing and Testing a Methodology for Analysis of the Staff Development Leadership Role.' Research in Post-Compulsory Education, 8(2) 249-263. Available at:

https://www.tandfonline.com/doi/abs/10.1080/13596740300200152 (Accessed: 11 August 2018).

Broecke, S. and Nicholls, T. (2007) Ethnicity and Degree Attainment. Department of Education and Skills Research Report No. RW92. Available at: https://www.education.gov.uk/publications/standard/publicationDetail/Page1/RW92 (Accessed: 21 December 2017).

Brookfield, S. (2016) 'Using Narrative and Team-Teaching to Address Teaching About Racial Dynamics.' In: Scott, C. and Sims, J. (eds.) Developing Workforce Diversity Programs, Curriculum and Degrees in Higher Education. Pennsylvania: IGI Publishing, 98116. ISBN: 1522502092

Cohen, M.D. and March, J.G. (1974) Leadership and ambiguity: The American college president. Boston: Harvard Business School Press. ISBN: 0875841317

Dovidio, J.F., Gaertner, S.L., Stewart, T.L., Esses, V.M. and ten Vergert, M. (2004) 'From intervention to outcomes: Processes in the reduction of bias.' In: Stephan, W.G. and Vogt, P. (eds.) Education programs for improving intergroup relations: Theory, research, and practice. New York: Teachers College Press, 243-265. ISBN: 080774459X

Eddo-Lodge, R. (2014) 'Why l'm no longer talking to white people about race.' (Blog post) Available at: http://renieddolodge.co.uk/why-im-no-longer-talking-to-white-people-about-race/ (Accessed: 11 August 2018).

Eddo-Lodge, R. (2017) Why I'm no longer talking to white people about race. London: Bloomsbury. ISBN: 140887055X

Elliott, J. (2017) 'Brown eyes blue eyes.' Available at: https://janeelliott.com/ (Accessed: 11 August 2018). 
Ellis, C. and Bochner, A.P. (2000) 'Autoethnography, personal narrative, reflexivity: Researcher as subject.' In: Denzin, N.K and Lincoln, Y.S. (eds.) Handbook of Qualitative Research. London: Sage, 733-768. ISBN: 0761915125

Equality Act (2010) Available at: http://www.legislation.gov.uk/ukpga/2010/15/contents (Accessed: 11 August 2018).

Equality Challenge Unit (2017) Equality in higher education: students statistical report 2016. Available at: https://www.ecu.ac.uk/guidance-resources/using-data-and-evidence/statisticsreport/ (Accessed: 21 December 2017).

Equality Challenge Unit (2018) Using data and evidence. Available at: https://www.ecu.ac.uk/guidance-resources/using-data-and-evidence/ (Accessed: 11 August 2018).

Kezar, A. (2008) 'Understanding Leadership Strategies for Addressing the Politics of Diversity.' The Journal of Higher Education, 79(4), 406-441. Available at:

https://www.tandfonline.com/doi/abs/10.1080/00221546.2008.11772109 (Accessed: 11 August 2018).

Kohli, R. (2008) 'Breaking the Cycle of Racism in the Classroom: Critical Race Reflections from Future Teachers of Color.' Teacher Education Quarterly, 177-188. Available at: https://eric.ed.gov/?id=EJ838707 (Accessed: 11 August 2018).

Lewis, M. (2008) 'Self-conscious emotions: Embarrassment, pride, shame, and guilt.' In: Lewis, M. and Haviland, J.M. (eds.) Handbook of emotions. New York: Guilford Press, 742756. ISBN: 1606238035

Marcuse, H. (1964) One dimensional man. Boston: Beacon. ISBN: 080701575X

Mclntosh, P. (1988) White privilege and male privilege: A personal account of coming to see correspondences through work in women's studies. Wellesley. Wellesley College, Center for Research on Women, 94-105.

Milton, C. (1972) Women in policing. Washington: Police Foundation.

Monteith, M.J., Voils, C.I. and Ashburn-Nardo, L. (2001) 'Taking a look underground:

Detecting, interpreting, and reacting to implicit racial biases.' Social Cognition, 19, 395-417.

Available at: https://guilfordjournals.com/doi/10.1521/soco.19.4.395.20759 (Accessed: 11

August 2018).

Narayan, K. (1993) 'How native is a 'native' anthropologist?' American Anthropologist, 95(3), 671-686. Available at:

https://anthrosource.onlinelibrary.wiley.com/doi/10.1525/aa.1993.95.3.02a00070 (Accessed: 11 August 2018).

Pendry, L.F., Driscoll, D.M. and Field, S.C.T. (2007) 'Diversity training: Putting theory into practice.' Journal of Occupational and Organizational Psychology, 80, 27-50. Available at: https://onlinelibrary.wiley.com/doi/abs/10.1348/096317906X118397 (Accessed: 11 August 2018). 
Pettigrew, T. and Tropp, L. (2000) 'Does intergroup contact reduce prejudice? Recent metaanalytic findings.' In: Oskamp, S. (ed.) Reducing prejudice and discrimination. Mahwah, NJ: Erlbaum, 93-114. ISBN: 0805834826

Project Implicit (2011) Implicit Association Tests. Available at:

https://implicit.harvard.edu/implicit/iatdetails.html (Accessed: 11 August 2018).

Society for Education and Training (2016) Critical Incident Analysis. Available at: https://set.et-foundation.co.uk/professionalism/teaching-resources/critical-incident-analysis/ (Accessed: 11 August 2018).

Sue, D.W. (2013) 'Race talk: the psychology of racial dialogues.' American Psychologist, 68(8), 663-72. Available at: https://psycnet.apa.org/record/2013-42570-019 (Accessed: 11 August 2018).

The video journal of education (2002) Closing the Achievement Gap. San Francisco: The LPD Video Journal of Education and Teach-Stream.

Stewart, T.L., La Duke, J.R., Bracht, C., Sweet, B.A.M. and Gamarel, K.E. (2003) 'Do the eyes have it? A program evaluation of Jane Elliott's Blue eyes/Brown eyes diversity training exercise.' Journal of Applied Social Psychology, 33, 1898-1921. Available at:

https://onlinelibrary.wiley.com/doi/abs/10.1111/j.1559-1816.2003.tb02086.x (Accessed: 11

August 2018).

Tuffour, I. (2018) 'Reflections of a black African insider researcher.' Nurse Researcher, 26(3). Available at: https://journals.rcni.com/nurse-researcher/evidence-andpractice/reflections-of-a-black-african-insider-researcher-nr.2018.e1570/abs. (Accessed: 21 January 2018). 